\title{
Experimental comparison of the dynamic evaporator response using homogeneous and slip flow modeling
}

\author{
Martin Ryhl Kærn ${ }^{\dagger} \star \quad$ Brian Elmegaard ${ }^{\dagger} \quad$ Lars Finn Sloth Larsen ${ }^{\ddagger}$ \\ ${ }^{\dagger}$ Technical University of Denmark, Department of Mechanical Engineering \\ Nils Koppels Allé Bygn. 403, DK-2800 Lyngby, Denmark, e-mail: pmak@mek .dtu.dk \\ † Danfoss A/S, Refrigeration and Air-Conditioning \\ Nordborgvej 81, DK-6430 Nordborg, Denmark, e-mail: martin@danfoss . com
}

\begin{tabular}{|c|c|c|}
\hline Abstract & $\begin{array}{l}h \\
\bar{h}\end{array}$ & $\begin{array}{l}\text { Specific mixed-cup enthalpy }\left(\mathrm{J} \mathrm{kg}^{-1}\right) \\
\text { Specific in situ mixture enthalpy }\left(\mathrm{J} \mathrm{kg}^{-1}\right)\end{array}$ \\
\hline \multirow{6}{*}{$\begin{array}{l}\text { The dynamic response from an evaporator is important } \\
\text { for control of refrigeration and air-conditioning sys- } \\
\text { tems. Essentially, the prediction of refrigerant charge } \\
\text { inside the evaporator is crucial for the dynamic behav- } \\
\text { ior. The prediction of refrigerant charge follows from } \\
\text { suitable void fraction correlations from the literature. }\end{array}$} & $h_{\mathrm{tc}}$ & Heat transfer coefficient $\left(\mathrm{W} \mathrm{m}^{-2} \mathrm{~K}^{-1}\right)$ \\
\hline & $\dot{I}$ & Momentum flow $(\mathrm{N})$ \\
\hline & $k$ & Thermal conductivity $\left(\mathrm{W} \mathrm{m}^{-1} \mathrm{~K}^{-1}\right)$ \\
\hline & $M$ & Mass (kg) \\
\hline & $\dot{m}$ & Mass flow rate $\left(\mathrm{kg} \mathrm{s}^{-1}\right)$ \\
\hline & $P$ & Channel perimeter $(\mathrm{m})$ \\
\hline \multirow{3}{*}{$\begin{array}{l}\text { A chosen set of void fraction correlations (slip flow) } \\
\text { and the assumption of homogeneous flow will be in- } \\
\text { vestigated in this paper and compared to experiments }\end{array}$} & $p$ & Pressure $(\mathrm{Pa})$ \\
\hline & $\dot{Q}$ & Heat flow rate $(\mathrm{W})$ \\
\hline & $q_{w}^{\prime \prime}$ & Wall heat flux $\left(\mathrm{W} \mathrm{m}^{-2}\right)$ \\
\hline \multirow{2}{*}{$\begin{array}{l}\text { on a simple coaxial type evaporator. The numerical } \\
\text { model of the evaporator is a dynamic distributed mix- }\end{array}$} & $R$ & Thermal resistance $\left(\mathrm{K} \mathrm{W}^{-1}\right)$ \\
\hline & $S$ & Slip ratio (-) \\
\hline \multirow{2}{*}{$\begin{array}{l}\text { ture model, where different void fraction correlations } \\
\text { can be applied. It is shown that the dynamic response }\end{array}$} & $T$ & Temperature $(\mathrm{K})$ \\
\hline & $t$ & Time (s) \\
\hline \multirow{2}{*}{$\begin{array}{l}\text { of the homogeneous model is too fast, whereas the slip } \\
\text { flow models agree well with the experiments. Another }\end{array}$} & $U$ & Velocity $\left(\mathrm{m} \mathrm{s}^{-1}\right)$ \\
\hline & $\dot{V}$ & Volume flow rate $\left(\mathrm{m}^{3} / \mathrm{s}\right)$ \\
\hline difference is that the charge prediction of the homoge- & $x$ & Vapor quality (-) \\
\hline $\begin{array}{l}\text { neous model is approximately } 2-3 \text { times less than the } \\
\text { slip flow models. }\end{array}$ & $\begin{array}{l}z \\
\text { Greek }\end{array}$ & Axial channel length (m) \\
\hline \multirow{5}{*}{$\begin{array}{l}\text { Keywords: refrigeration; air-conditioning; evapo- } \\
\text { rator; two-phase flow; modeling; Modelica; transient; } \\
\text { dynamic; simulation }\end{array}$} & $\alpha$ & Void fraction (-) \\
\hline & $\rho$ & Density $\left(\mathrm{kg} \mathrm{m}^{-3}\right)$ \\
\hline & $\bar{\rho}$ & Mixture density $\left(\mathrm{kg} \mathrm{m}^{-3}\right)$ \\
\hline & $\rho^{\prime}$ & Momentum density $\left(\mathrm{kg} \mathrm{m}^{-3}\right)$ \\
\hline & $\sigma$ & Surface tension $\left(\mathrm{N} \mathrm{m}^{-1}\right)$ \\
\hline \multirow[t]{2}{*}{ Nomenclature } & $\theta$ & Angle to horizontal plane (deg.) \\
\hline & Subscr & ripts \\
\hline Roman & ax & Axial \\
\hline$A \quad$ Cross-sectional area $\left(\mathrm{m}^{2}\right)$ & $b$ & Brine \\
\hline Specific heat capacity $\left(\mathrm{J} \mathrm{kg}^{-1} \mathrm{~K}^{-1}\right)$ & $f$ & Saturated liquid \\
\hline Inner tube outer diameter $(\mathrm{m})$ & $g$ & Saturated gas \\
\hline Inner tube inner diameter $(\mathrm{m})$ & $H$ & Homogeneous \\
\hline Wall friction force $\left(\mathrm{N} \mathrm{m}^{-3}\right)$ & $\mathrm{rad}$ & Radial \\
\hline Mass flux $\left(\mathrm{kg} \mathrm{m}^{-2} \mathrm{~s}^{-1}\right)$ & sat & Saturation \\
\hline Gravitational acceleration $\left(\mathrm{m} \mathrm{s}^{-2}\right)$ & $w$ & Wall \\
\hline Enthalpy flow (W) & & \\
\hline
\end{tabular}




\section{Introduction}

Refrigerant charge minimization in refrigeration and air-conditioning systems is becoming increasingly important for environmental and legislative reasons. As the charge is minimized the dynamic behavior of the system becomes quicker and the requirements for the control increases. Furthermore, new control methods continuously evolve that requires more and more accurate prediction of the dynamic behavior of the evaporator. Thus there is a demand for accurate modeling of the evaporator response.

The focus in this paper is the modeling of the dynamic behavior in a dry-expansion evaporator with experimental validation. The key variable here is the void fraction. The void fraction essentially determines the refrigerant charge and thus the dynamic response of the evaporator. As we shall see in section 4, the use of a void fraction correlation determines the slip ratio of the two phases, implying a slip flow model. If the slip ratio is assumed to be unity, then the flow is homogeneous (i.e. both phases travel with the same velocity), implying the homogeneous model.

Many void fraction correlations exist in the literature. Some are rather simple analytical relations, others are quite sophisticated and of empirical nature. The question in mind is: When is it sufficient to use the homogeneous model, in contrast to the slip flow models?

Despite the large amount of work that has been done on the development of void fraction correlations, some void fraction correlations do not satisfy a smooth transition in void fraction at the two-phase to vapor phase transition. Woldesemayat and Ghajar [1] compared 68 void fraction correlations in order to find an acceptable void fraction correlation that could predict most of the collected experimental data for all inclination angles, fluids and flow patterns. They developed a modified version of the Dix [2] model, however, the model does not ensure a smooth transition at the two-phase to vapor phase transition. For dynamic simulation the transition and its derivatives should be continuous or at least a smoothening may be used. Furthermore, the correlation complexity should be sought to a minimum while capturing the main dynamics of interest.

Woldesemayat and Ghajar [1] also gave void fraction correlation recommendations, considering each specific type of flow. For horizontal flow, as is the case of consideration in this paper, the void fraction of Premoli et al. [3] was worth the general recommendation among others, regardless of flow regime and fluids. Recently, the same void fraction model was recommended by Maa et al. [4] and Mader et al. [5] as the best choice for R410A air-conditioners. The model also ensures a smooth transition at the two-phase to vapor-phase transition, and for these reasons the Premoli et al. [3] model will be used in this study.

Wojtan et al. [6] recommends Steiners version of the Rouhani and Axelsson void fraction model [7], and uses this model in their general flow map [8] for predicting both two-phase heat transfer and pressure drop in a flow regime dependant way. The earlier versions of the Rouhani and Axelsson model did not ensure a smooth transition from two-phase to vapor phase, however Steiner modified the model for horizontal flow in a way that ensures a smooth transition. The Steiner version of the Rouhani and Axelsson model is also included in this study.

The two aforementioned void fraction correlations are both sophisticated models and functions of pressure, $p$, vapor quality, $x$, mixture mass flux, $G$, surface tension, $\sigma$, and acceleration of gravity, $g$. Simpler models only dependant on pressure and vapor quality exists, e.g. the Zivi [9] model, which is one of the simplest void fraction models. The inclusion of the Zivi [9] model fulfills our set of slip flow models to be investigated in this paper.

The paper includes a brief description of the experiments, the test rig and the numerical modeling framework. Then the results of the transient evaporator response are addressed.

\section{The experiments}

The experimental data are obtained from the master thesis of Antonius [10], who compared the experimental results with commercial software Sinda/Fluint [11]. The thesis is written in Danish, however the main results are given in English in Jakobsen et al. [12]. Sinda/Fluint is a general thermo-fluid network analyzer capable of simulating static and dynamic behavior of multi-phase fluid networks as they interact with thermal structures, using a lumped parameter finitedifference approach. It is quite similar to the numerical model introduced in section 4 , however the empirical correlations for heat transfer, friction coefficient and void fraction are restricted to a predefined possibilities.

The test case geometry and boundary conditions were kept as simple as possible in order to focus on the two-phase flow. Figure 1 shows a sketch of the test case coaxial evaporator and corresponding boundary conditions for the numerical simulations. The outer tube wall is insulated to minimize heat flow from the 


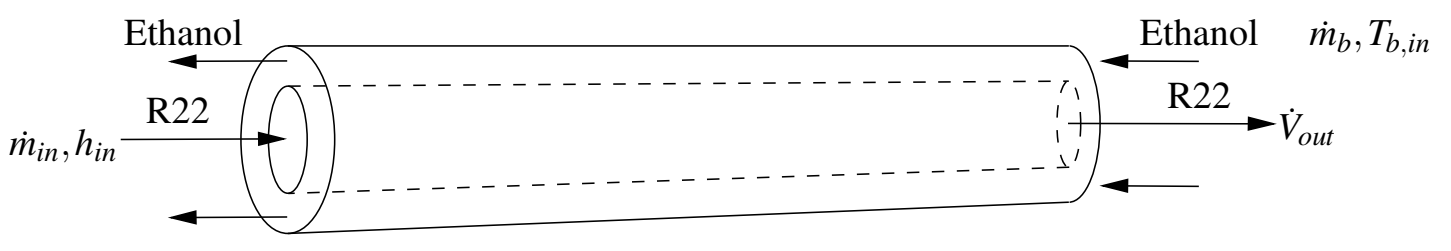

Figure 1: Sketch of test case evaporator

surroundings. R22 is the refrigerant flowing in the inner tube, whereas ethanol with $10 \%$ water by mass is flowing in countercurrent direction in the outer tube shell.

Both a step in refrigerant mass inflow and volume outflow was considered in the work by Antonius [10]. The original data does unfortunately no longer exist, however, the boundary conditions as function of time, as indicated on figure 1, was curve fitted in the work to be used as input to Sinda/Fluint. Only one set of these curve fits is available in the thesis, whereas the rest are missing. For these reasons it is only possible to reproduce the evaporator response on a step change in volume outflow. The dynamics of the mass outflow and outlet pressure is then compared to the homogeneous model and slip flow models. The mass inflow, mass outflow and outlet pressure are obtained from figures in Antonius [10] by graphical means for the comparison.

\section{The test rig}

A schematic of the test rig is shown in figure 2. The test case coaxial evaporator is $7 \mathrm{~m}$ long and made of cobber. The inner tube has an internal and outer diameter of 11.1 and $12.7 \mathrm{~mm}$, respectively, and the outer tube outer diameter is $20.18 \mathrm{~mm}$.

The following data are used to obtain the appropriate boundary conditions as shown in figure 1 . At the inlet of the evaporator, the mass flow is measured directly by M2, the mixed-cup enthalpy $h$ is found using the subcooled liquid temperature T3 and pressure P1. The volume flow at the outlet of the evaporator is found using the mass flow M1 and the density of the superheated vapor at temperature $\mathrm{T} 1$ and pressure $\mathrm{P} 3$. The mass flow M3 and temperature T4 are directly applicable as boundary conditions for the brine system.

A thorough documentation of the test rig (e.g. apparatus, calibration and data acquisition method) can be found in Antonius [10].

\section{Model formulation}

The model is implemented in Dymola 7.4 [13]. Dymola is based on the Modelica language and facilitates object-oriented programming, which is important for model reuse and extension. Dymola has been well tested within the field of air-conditioning and refrigeration $[14,15]$. Thermophysical properties for R22 are obtained from the Refeqns package [16]. Thermophysical properties for ethanol with $10 \%$ water by mass are obtained from VDI Wärmeatlas [17].

\subsection{Refrigerant flow}

The simplest form of the one-dimensional two-phase flow models is chosen, i.e. the mixture model as derived by performing a differential analysis on each phase and adding the phasic equations [18]. The result is the mixture mass conservation, the mixture momentum conservation and the mixture energy conservation equations given by

$$
\begin{gathered}
A \frac{\partial \bar{\rho}}{\partial t}+\frac{\partial \dot{m}}{\partial z}=0 \\
\frac{\partial \dot{m}}{\partial t}+\frac{\partial}{\partial z}\left(\frac{\dot{m}^{2}}{\rho^{\prime} A}\right)=-A \frac{\partial p}{\partial z}-F_{w} A-\bar{\rho} g A \sin \theta \\
A \frac{\partial}{\partial t}(\bar{\rho} \bar{h}-p)+\frac{\partial}{\partial z}(\dot{m} h)=P q_{w}^{\prime \prime}
\end{gathered}
$$

where it has been assumed that thermodynamic equilibrium exists and that the changes in kinetic and potential energy are negligible. The mixture density, specific in situ enthalpy, specific mixed-cup enthalpy and momentum density are given by

$$
\begin{gathered}
\bar{\rho}=\rho_{g} \alpha+\rho_{f}(1-\alpha) \\
\bar{h}=\left[\rho_{f} h_{f}(1-\alpha)+\rho_{g} h_{g} \alpha\right] / \bar{\rho} \\
h=(1-x) h_{f}+x h_{g} \\
\rho^{\prime}=\left(\frac{(1-x)^{2}}{\rho_{f}(1-\alpha)}+\frac{x^{2}}{\rho_{g} \alpha}\right)^{-1}
\end{gathered}
$$

where the void fraction is defined as $\alpha=A_{g} / A$, and the vapor quality is defined as $x=\dot{m}_{g} / \dot{m}$. 


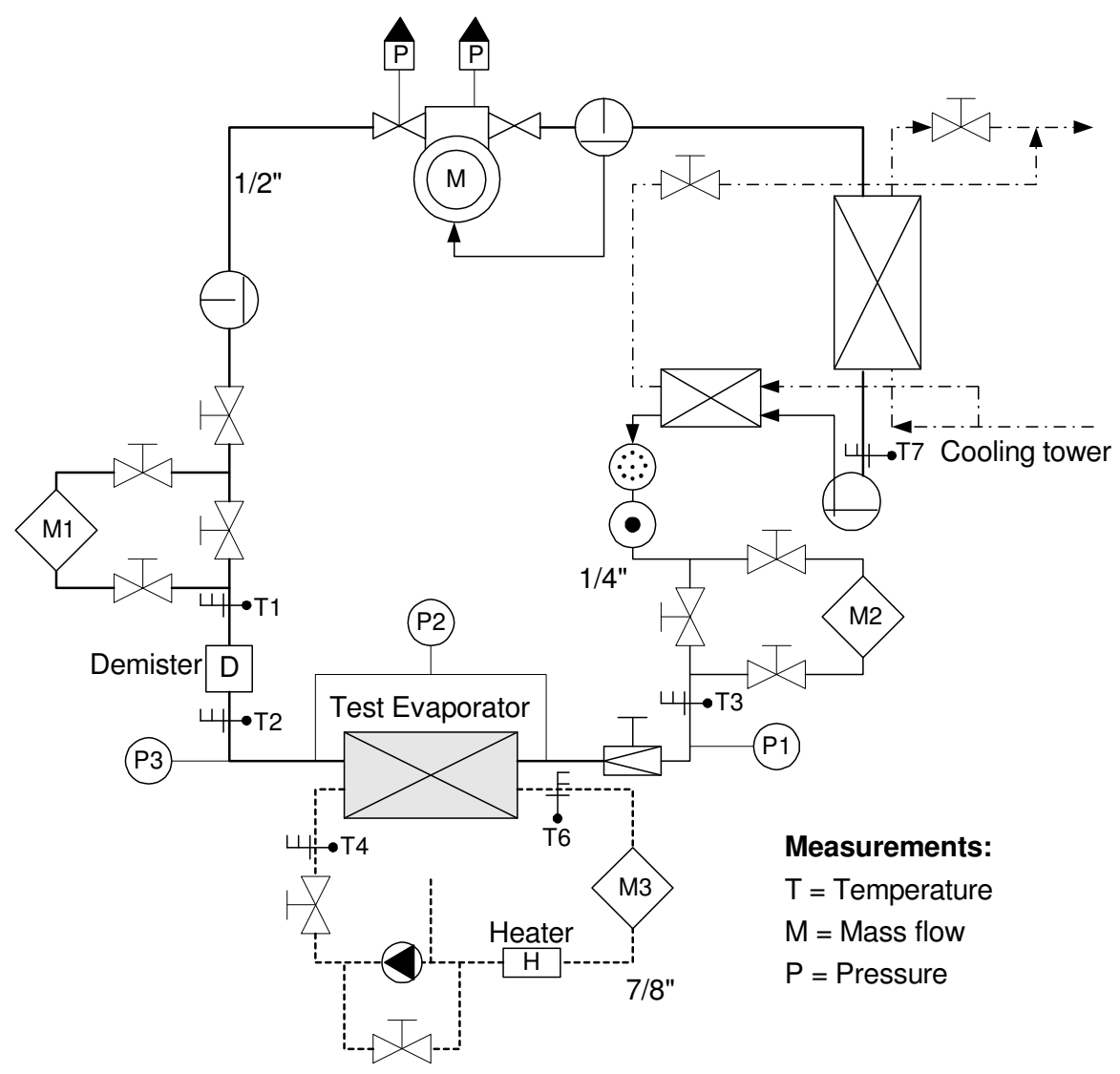

Figure 2: Evaporator test rig

Using the definition of the slip ratio, the void fraction and the vapor quality, the fundamental voidquality relation can be derived as

$$
\begin{aligned}
S & =\frac{U_{g}}{U_{f}}=\frac{\frac{\dot{m}_{g}}{\rho_{g} \alpha A}}{\frac{\dot{m}_{f}}{\rho_{f}(1-\alpha) A}} \\
& =\frac{x}{1-x} \frac{\rho_{f}}{\rho_{g}} \frac{1-\alpha}{\alpha}
\end{aligned}
$$

and rewritten in terms of the void fraction as

$$
\alpha=\left[1+\frac{\rho_{g}}{\rho_{f}} \frac{1-x}{x} S\right]^{-1}
$$

If homogeneous flow is assumed, then $S=1$ and the homogeneous void fraction, $\alpha_{H}$, may be calculated by equation 9. Furthermore, for homogeneous flow it can be shown that $\bar{h}=h$ and $\rho^{\prime}=\bar{\rho}=\rho_{H}$ by using the homogeneous void fraction, where the homogeneous mixture density, $\rho_{H}$, becomes

$$
\rho_{H}=\left(\frac{x}{\rho_{g}}+\frac{1-x}{\rho_{f}}\right)^{-1}
$$

The state variables are chosen to be $\bar{h}$ and $p$. The derivative of the mixture density with respect to time is computed by use of the chain rule

$$
\frac{\partial \bar{\rho}}{\partial t}=\left.\frac{\partial \bar{\rho}}{\partial p}\right|_{\bar{h}} \frac{\partial p}{\partial t}+\left.\frac{\partial \bar{\rho}}{\partial \bar{h}}\right|_{p} \frac{\partial \bar{h}}{\partial t}
$$

where the partial derivatives of mixture density with respect to pressure and in situ enthalpy are calculated by numerical finite difference as

$$
\begin{aligned}
& \left.\frac{\partial \bar{\rho}}{\partial p}\right|_{\bar{h}}=\frac{\bar{\rho}(p+\Delta p, \bar{h})-\bar{\rho}(p, \bar{h})}{\Delta p} \\
& \left.\frac{\partial \bar{\rho}}{\partial \bar{h}}\right|_{p}=\frac{\bar{\rho}(p, \bar{h}+\Delta \bar{h})-\bar{\rho}(p, \bar{h})}{\Delta \bar{h}}
\end{aligned}
$$

Equations 1, 2 and 3 are discretized according to the Finite Volume Method (FVM), where the number of control volumes must be high enough to resolve the spatial distribution of properties.

The staggered grid structure is adopted as described by Patankar [19]. It means that the mass and energy conservation will be solved on the control volume grid, and the momentum equation will be solved on a staggered grid as depicted on figure 3, where $\psi$ denotes 
a thermodynamic quantity and $\hat{\psi}$ its approximation. Similar discretization methodology was used in [20].

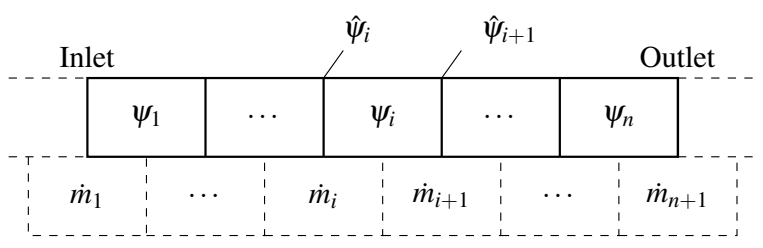

Figure 3: Staggered grid structure; thick $=$ control volume grid, dashed $=$ staggered grid

The mass and energy conservation equations become

$$
\begin{gathered}
A \Delta z \frac{d \bar{\rho}_{i}}{d t}=\dot{m}_{i}-\dot{m}_{i+1} \\
A \Delta z \frac{d}{d t}\left(\bar{\rho}_{i} \bar{h}_{i}-p_{i}\right)=\dot{H}_{i}-\dot{H}_{i+1}+\dot{Q}_{i}
\end{gathered}
$$

where the enthalpy flow $\dot{H}_{i}=\dot{m}_{i} \hat{h}_{i}$ and heat flow $\dot{Q}_{i}=$ $P \Delta z q_{w, i}^{\prime \prime}=P \Delta z h_{\mathrm{tc}, \mathrm{i}}\left(T_{w, i}-T_{i}\right)$ have been used, and Newton's law of cooling is applied with the well known heat transfer coefficient $h_{\mathrm{tc}}$.

For convection dominated flows the upwind difference scheme is recommended to approximate thermodynamic quantities onto the staggered grid, because central difference scheme may lead to non-physical solutions. The $1^{\text {st }}$ order upwind scheme is obtained by taking the control volume face value (staggered grid center) to be equal to the nearest upstream control volume center, thus

$$
\hat{\psi}_{i} \approx \delta_{i} \psi_{i}+\left(1-\delta_{i}\right) \psi_{i-1} \quad i=1 . . n+1
$$

where $\delta_{i}$ is the indicator function denoting the direction of the mass flow

$$
\delta_{i}=\left\{\begin{array}{cc}
0 & \dot{m} \geq 0 \\
1 & \dot{m}<0
\end{array}\right.
$$

The momentum equation becomes

$$
\begin{array}{r}
\Delta z \frac{d \dot{m}_{i}}{d t}=\Delta \dot{I}_{i}-A\left(p_{i}-p_{i-1}\right)-F_{w, i} A \Delta z \\
-\hat{\bar{\rho}}_{i} g A \Delta z \sin \theta
\end{array}
$$

where the momentum flow $\dot{I}_{i}=\dot{m}_{i}^{2} /\left(\hat{\rho}_{i}^{\prime} A\right)$ has been used and the difference in momentum flow, $\Delta \dot{I}_{i}$, is approximated according to the $2^{\text {nd }}$ order central difference scheme as

$$
\Delta \dot{I}_{i} \approx \frac{\left(\dot{I}_{i-1}-\dot{I}_{i}\right)+\left(\dot{I}_{i}-\dot{I}_{i+1}\right)}{2}=\frac{d \dot{I}_{i-1}+d \dot{I}_{i}}{2}
$$

where $d \dot{I}$ is the momentum flow difference between the staggered grid cells. The use of the central difference scheme serves to avoid discontinuities in the momentum equation.

Boundary models are used to compute other boundary conditions than the ones indicated on figure 1, i.e. $\dot{H}, \dot{I}, d \dot{I}, \hat{\psi}$. The change of momentum flow $d \dot{I}$ at the inlet or outlet is simply set to zero, whereas the other variables are computed from the thermodynamic state and the mass flow rate.

Correlations for the frictional force, $F_{w}$, the heat transfer coefficient, $h_{\mathrm{tc}}$, and the void fraction, $\alpha$ (if slip flow), must be supplied to close the system of equations.

\subsection{Tube wall}

The tube wall is discretized according to the Resistance Capacitance Method [21]. The method essentially uses the thermal resistances to describe the heat flows across the tube wall boundaries. The tube wall is assumed to have rotational symmetry, i.e. $T=T(r, z)$, and thus the energy equation for each discrete cell becomes

$$
M c_{p} \frac{d T}{d t}=\dot{Q}_{W}+\dot{Q}_{E}+\dot{Q}_{S}+\dot{Q}_{N}
$$

where $\dot{Q}_{S}=-P \Delta z q_{w}^{\prime \prime}$ from equation 3. The entering and leaving heat flows are depicted on figure 4 .
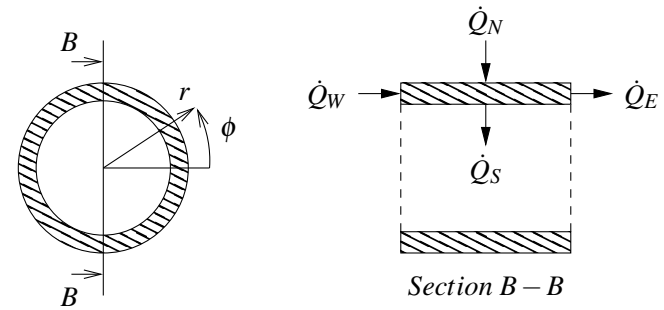

Figure 4: Heat flows to and from the tube wall

By definition, the heat flows are computed as $\dot{Q}=$ $\Delta T / R$, where the thermal resistances in the radial and axial directions to the midpoint of the wall cell are

$$
\begin{gathered}
R_{\mathrm{ax}}=0.5 \frac{\Delta z}{k A} \\
R_{\mathrm{rad}}=0.5 \frac{\ln \frac{D / 2}{d / 2}}{2 \pi k \Delta z}
\end{gathered}
$$

The boundary condition at the inlet and outlet of the pipe wall is simply no heat flow in the axial direction. 


\subsection{Liquid flow}

The liquid flow is assumed to be incompressible and cannot accumulate mass or energy. With these assumptions the mass and energy conservation equations for each liquid cell reads

$$
\begin{gathered}
\dot{m}_{\mathrm{in}}-\dot{m}_{\mathrm{out}}=0 \\
\left(\dot{m} c_{p} T\right)_{\text {in }}-\left(\dot{m} c_{p} T\right)_{\text {out }}+\dot{Q}_{N}=0
\end{gathered}
$$

Again Newton's law of cooling is applied to compute the heat transfer as

$$
\dot{Q}_{N}=h_{\mathrm{tc}} \Delta z P\left(T_{w}-T_{\mathrm{in}}\right)
$$

where the $1^{\text {st }}$ order upwind approximation of the liquid cell temperature is used. A correlation for the heat transfer coefficient must be applied.

\subsection{Smooth functions}

A first order continuous function is applied at the phase transitions $(0 \leq x<0.05$ and $0.95<x \leq 1)$. The function ensures a smooth transition from two-phase to single phase in heat transfer and frictional pressure drop correlations. If the transitions are discontinuous, the equation solver might be slow or even fail to converge. The first order continuous function is described in Richter [15]. The used correlations are shown in table 1.

\subsection{Heat exchanger architecture}

Components of the refrigerant (both control volume grid cell and staggered grid cell), the wall and the liquid have been made in Dymola, and essentially arrays of these components are put together to form the evaporator in counter flow operation, as shown on figure 5.

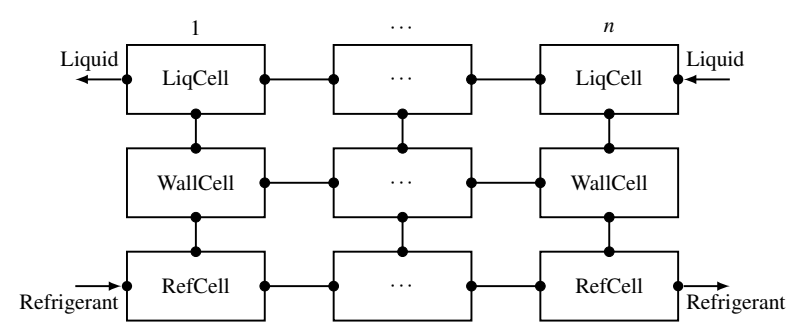

Figure 5: Heat exchanger architecture, counter flow.

We chose to use 30 cells in our simulations. Furthermore, we did not use any of the elements of the Modelica standard library. We chose this to learn every step of the implementation in Modelica and to be
Table 1: Overview of used correlations

\begin{tabular}{ll}
\hline $\begin{array}{l}\text { Liquid brine } \\
\text { Heat transfer }\end{array}$ & Dittus and Boelter [22] \\
\hline $\begin{array}{l}\text { Single phase refrigerant } \\
\text { Heat transfer }\end{array}$ & Gnielinski [23] \\
Friction & Blasius [24] \\
\hline Two-phase refrigerant & \\
Heat transfer & Shah [25] \\
Friction & Müller-Steinhagen and \\
& Heck [26] \\
Void fraction & Zivi [9] \\
& Premoli et al. [3] \\
& Steiners version of Rouhani \\
& and Axelsson [7] \\
\hline
\end{tabular}

able to quickly apply changes to the model formulation and correlations if necessary.

\section{Results}

In this section, the results are compared to the experimental data at a step decrease or increase in volume outflow. The cases correspond to a change in outflow by capacity control of the compressor. Firstly, we address the different void fraction correlations to be used.

\subsection{Comparison of the void fraction models}

All the used correlations for the void fraction (slip flow models) are shown in table 1.

Using equation 9 with $S=1$ becomes the homogeneous model, where each phase travels with the same velocity. If we use the slip ratio correlation by Zivi [9] in equation 9, i.e. $S=\left(\rho_{g} / \rho_{f}\right)^{-1 / 3}$, we get the Zivi void fraction model. The Premoli et al. [3] model and the Steiners version of the Rouhani and Axelsson model [7] depend on both flow and fluid properties in more complicated ways. The void fraction models are compared in figure 6 as functions of vapor quality.

It is clearly seen that the area of the liquid is smaller in the homogeneous model, indicating a faster dynamic response compared to all the other models. The Premoli model and the Steiners version of the Rouhani and Axelsson model seam almost the same for the specific refrigerant and conditions. At low vapor qualities the Zivi model shows the largest amount of liquid, however at vapor qualities above 0.2 , which is often the case for dry-expansion systems, it shows less liquid than the Premoli model and the Steiners version of the Rouhani and Axelsson model, indicating a faster 


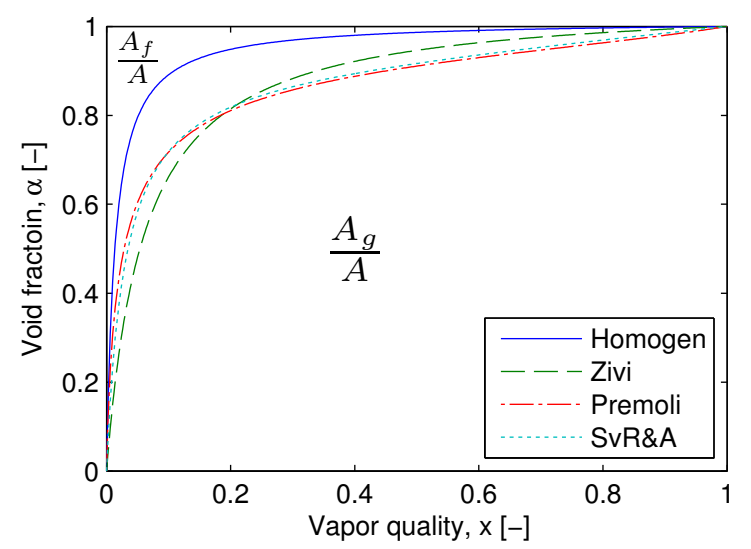

Figure 6: Comparison of the chosen void fraction models. (R22, $T_{\mathrm{sat}}=-5.7^{\circ} \mathrm{C}, p=4.12$ bar, $G=124$ $\mathrm{kg} \mathrm{m}^{-2} \mathrm{~s}^{-1}$ )

dynamic response, however, not as fast as the homogeneous model.

\subsection{A step decrease in volume outflow}

In figure 7, the response of the mass outflow and the outlet pressure are compared at a step decrease in volume outflow.

At time equal 5 seconds the step occurs. The step shows an undershoot in mass outflow in the experiment and the models. The models have a sharp edge at the peak of the undershoot, which originates from the curve fitted boundary condition for volume outflow. After the undershoot the mass outflow increases and adjusts to a new steady state after approximately 40 seconds. Only the homogeneous model shows an overshoot during the transient response. Similarly, the pressure increases as the volume outflow decreases, however, only the homogeneous model shows an overshoot here.

\subsection{A step increase in volume outflow}

In figure 8, the response of the mass outflow and the outlet pressure are compared at a step increase in volume outflow.

At time equal 7 seconds the increase in volume outflow occurs. The step shows a quite large overshoot in the mass outflow, however, it adjusts quicker to the new quasi-steady state after approximately $25 \mathrm{sec}-$ onds. Again the homogeneous model shows another undershoot after the overshoot. The pressure decreases on the step increase of volume outflow. Again the homogeneous model shows an undershoot in contrast to the other void fraction models. (a)

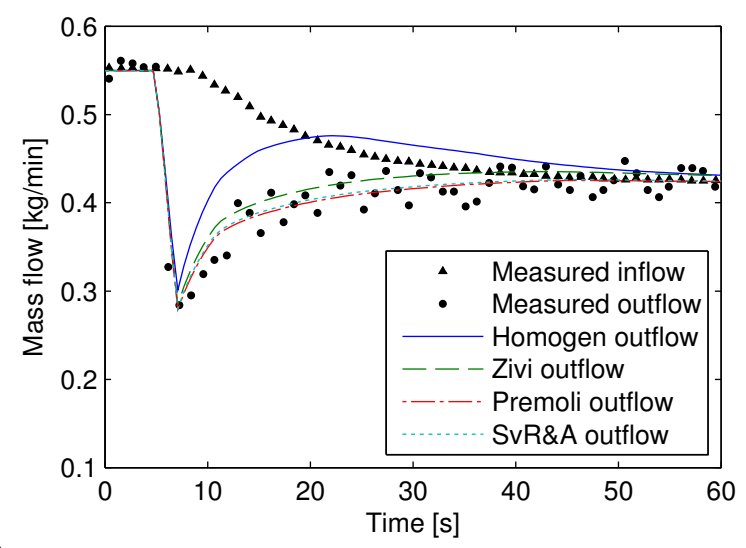

(b)

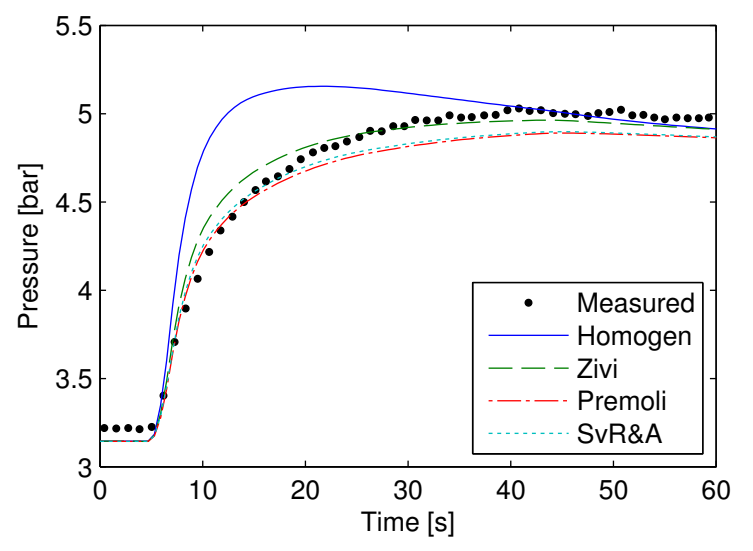

Figure 7: Mass outflow (a) and pressure outlet (b) response on decrease in volume outflow

\subsection{Discussion}

Apparently, the homogeneous model reacts too quickly. The response of the Premoli model and the Steiners version of the Rouhani and Axelsson model seam to predict almost the same and the most accurate responses from the evaporator. The Zivi model seam to be quite close to the experimental data, and can be considered as an easy way to capture the main dynamics of the evaporator, however, if the dynamics are more important, one should turn to the more sophisticated void fraction models.

Another observation is that the steady state values are not affected by the individual void fraction models. This is because the two-phase heat transfer and frictional pressure drop correlations are functions of vapor quality and not the choice of the void fraction correlation. Some more sophisticated two-phase heat transfer and frictional pressure drop correlations incorporate their own void fraction correlation in for example their heat transfer correlation [27]. One may inspect the equations 1,2 and 3 and find that almost only the dynamic terms are affected by the void frac- 
(a)

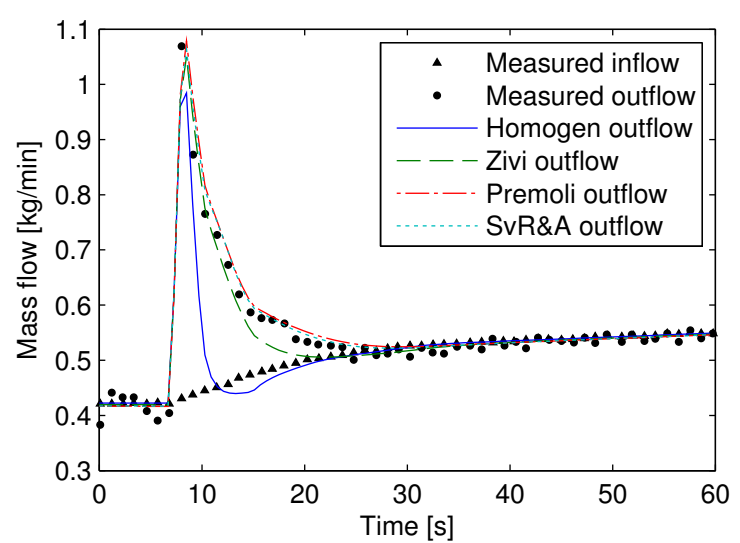

(b)

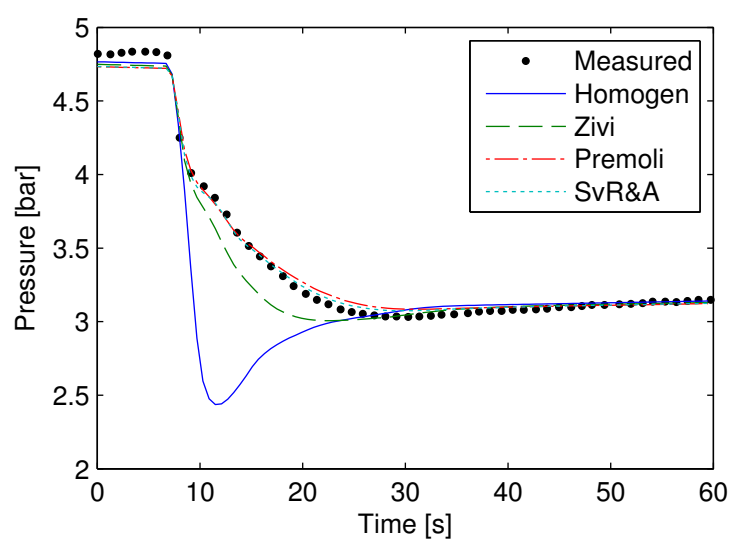

Figure 8: Mass outflow (a) and pressure outlet (b) response on increase in volume outflow

tion model. Other terms that are affected by the choice of void fraction model are the accelerational and gravitational pressure drop terms. For horizontal flow gravitational pressure drop vanish, however, usually both these terms are approximately an order of magnitude less than the frictional pressure drop $[15,28]$. Furthermore, they do not influence the heat transfer and corresponding evaporation pressure.

The refrigerant charge in the evaporator (both twophase and superheated area) are shown in table 2 at time equals 0 from figure 7 and 8 , i.e. the two different steady states.

Table 2: Refrigerant charge in the evaporator at time $=0$ from figure 7 and 8

\begin{tabular}{lcccc}
\hline & $\begin{array}{c}\text { Homogen } \\
{[\mathrm{g}]}\end{array}$ & $\begin{array}{c}\text { Zivi } \\
{[\mathrm{g}]}\end{array}$ & $\begin{array}{c}\text { Premoli } \\
{[\mathrm{g}]}\end{array}$ & $\begin{array}{c}\text { SvR\&A } \\
{[\mathrm{g}]}\end{array}$ \\
\hline $\mathrm{ss}^{*}$ (figure 7) & 10.7 & 16.8 & 24.0 & 22.6 \\
$\mathrm{ss}^{*}$ (figure 8) & 26.3 & 57.9 & 79.8 & 76.2 \\
\hline * ss $=$ steady state $($ at time & $=0$ ) & &
\end{tabular}

The two-phase area was approximately $35 \%$ of the evaporator at time $=0$ from figure 7 , however, on figure 8 at time $=0$ the two-phase area was approximately $85 \%$ in the evaporator. This leads to the differences in the refrigerant charge predictions from the steady states in figure 7 to 8 at time $=0$. When the volume flow goes down the pressure increases, both the overall UA-value and temperature difference between the refrigerant and the brine decreases, and it results in a smaller heat transfer and larger two-phase area. In other words, the refrigerant will be sucked out of the evaporator as the volume outflow increases at no control of the superheat.

Using the Premoli model and the Steiners version of the Rouhani and Axelsson model, as the most accurate void fraction models, shows that the homogeneous model underpredicts the refrigerant charge by approximately 2-3 times. The Zivi model lies in between.

\section{Conclusion}

It can be concluded that the homogeneous model is insufficient for modeling of the dynamic evaporator response of the current coaxial evaporator with high accuracy. If one wants to investigate the dynamic behavior due to refrigerant movement and amount of refrigerant in the evaporator, then a slip flow model is needed, since the homogeneous model gives inaccurate results. The choice of a given slip flow model must be considered for both numerical and accuracy reasons, which unfortunately are counteracting.

In this study the Premoli et al. [3] void fraction model and the Steiners version of the Rouhani and Axelsson [7] void fraction model gave the most accurate evaporator response. The simple void fraction model by Zivi [9] gave less accurate results, but quite much better than the homogeneous void fraction model.

These investigations considered a step in volume outflow, but similar conclusions with regard to voidfraction model validity are expected for a step in mass inflow to the evaporator, as pointed out in $[10,12]$. Investigation of the control strategy of a capacity controlled compressor or an expansion valve using the measured superheat as feedback, are examples, where the use of a slip flow model is required.

\section{References}

[1] M. A. Woldesemayat, A. J. Ghajar, Comparison of void fraction correlations for different flow patterns in horizontal and upward inclined pipes, 
International Journal of Multiphase Flow 33 (4) (2007) $347-370$.

[2] G. E. Dix, Vapor void fraction for forced convection with subcooled boiling at low flow rates, Tech. rep., General Electric Company Report NEDO-10491 (1971).

[3] A. Premoli, D. D. Francesco, A. Prina, A dimensional correlation for evaluating two-phase mixture density, La Termotecnica 25 (1971) 17-26.

[4] X. Maa, G. Dinga, P. Zhanga, W. Hana, S. Kasaharab, T. Yamaguchib, Experimental validation of void fraction models for $\mathrm{r} 410 \mathrm{a}$ air conditioners, International Journal of Refrigeration 32 (2009) 780-790.

[5] G. Mader, L. F. S. Larsen, G. P. F. Fösel, Low charge system behavior - interactions of heat exchanger volumes and charge, in: 2nd Workshop on Refrigerant Charge Reduction, IIR, KTH, Stockholm, Sweden, 2010.

[6] L. Wojtan, T. Ursenbacher, J. R. Thome, Measurement of dynamic void fractions in stratified types of flow, Experimental Thermal and Fluid Science 29 (3) (2005) $383-392$.

[7] D. Steiner, Heat transfer to boiling saturated liquids, VDI-Wärmeatlas (VDI Heat Atlas), Verein Deutscher Ingenieure (Ed.), VDI-Gessellschaft Verfahrenstechnik und Chemie-ingenieurwesen (GCV), Düsseldorf, 1993, (Translator: J.W. Fullarton).

[8] L. Wojtan, T. Ursenbacher, J. R. Thome, Investigation of flow boiling in horizontal tubes: Part $\mathrm{i}$ - a new diabatic two-phase flow pattern map, International Journal of Heat and Mass Transfer 48 (2005) 2955-2969.

[9] S. M. Zivi, Estimation of steady-state steam void-fraction by means of the principle of minimum entropy production, J. Heat Transf. 86 (1964) 247-252.

[10] J. Antonius, Distribuerede fordampermodeller på flere detaljeringsniveauer, Master's thesis, Technical University of Denmark, Department of Energy Engineering (1998).

[11] Cullimore \& Ring Technologies Inc., Littleton, Colorado, USA, Sinda/Fluint user's manual, General Purpose Thermal/Fluid Network Analyzer, version 5.2 (2008).
[12] A. Jakobsen, J. Antonius, H. J. Høgaard Knudsen, Experimental evaluation of the use of homogeneous and slip-flow two-ophase dynamic models in evaporator modelling, in: 20th International Congress of Refrigeration, IIR/IIF, Sydney, 1999.

[13] Dynasim AB, Research Park Ideon SE-223 70, Lund, Sweden, Dynamic Modeling Laboratory, Dymola User's Manual, version 7.4 (2010).

[14] J. Eborn, H. Tummescheit, K. Prölß, Airconditioning - a modelica library for dynamic simulation of ac systems, in: 4th International Modelica Conference, Hamburg, Germany, 2005, pp. 185192.

[15] C. C. Richter, Proposal of new object-oriented equation-based model libraries for thermodynamic systems, Ph.D. thesis, Technische Universität Carolo-Wilhelmina zu Braunschweig, Fakultät für Maschinenbau (2008).

[16] M. J. Skovrup, Thermodynamic and thermophysical properties of refrigerants, Department of Energy Engineering, Technical University of Denmark, Nils Koppels Allé, Building 402, DK-2800 Lyngby, Denmark (2009).

[17] VDI Wärmeatlas, Berechnungsblätter für den Wärmeübergang, Springer-Verlag, Ch. Lab., 9th Edition, Dd 20, (2002).

[18] S. M. Ghiaasiaan, Two-phase flow: Boiling and Condensation in Conventional and Miniature Systems, 1st Edition, Cambridge University Press, 2008.

[19] S. V. Patankar, Numerical heat transfer and fluid flow, Taylor \& Francis, 1980.

[20] O. Bauer, Modelling of two-phase flows with modelica, Master's thesis, Lund University, Department of Automatic Control (1999).

[21] A. F. Mills, Heat Transfer, 2nd Edition, Prentice Hall, 1999.

[22] E. J. Dittus, L. M. K. Boelter, Publications on Engineering, Vol. 2, University of California, Berkeley, 1930.

[23] V. Gnielinski, New equation for heat and mass transfer in turbulent pipe and channel flow, International Chemical Engineering 16 (1976) 359368. 
[24] P. R. H. Blasius, VDI Wärmeatlas, 9th Edition, Springer-Verlag, Ch. Lab., 2002.

[25] M. M. Shah, Chart correlation for saturated boiling heat transfer: Equations and further study, ASHRAE Transactions 88 (1982) 185-196.

[26] H. Müller-Steinhagen, K. Heck, A simple friction pressure drop correlation for two-phase flow in pipes, Chemical engineering and processing 20 (1986) 297-308.

[27] L. Wojtan, T. Ursenbacher, J. R. Thome, Investigation of flow boiling in horizontal tubes: Part ii - development of a new heat transfer model for stratified-wavy, dryout and mist flow regimes, International Journal of Heat and Mass Transfer 48 (2005) 2970-2985.

[28] H. Jiang, Development of a simulation and optimization tool for heat-exchanger design, Ph.D. thesis, University of Maryland at College Park, Department of Mechanical Engineering (2003). 